Correlation Between Resistance to UV Irradiation and the Taxonomic

EREM 77/1

Journal of Environmental Research, Engineering and Management Vol. 77 / No. 1 / 2021 pp. $67-75$

DOI 10.5755/j01.erem.77.1.23832

\section{Position of Microorganisms}

Received 2019/07

Accepted after revision 2021/02

\title{
Correlation Between Resistance to UV Irradiation and the Taxonomic Position of Microorganisms
}

\author{
Galina Gladka*, Vira Hovorukha, Victoria Romanovskaya, Oleksandr Tashyrev \\ Zabolotny Institute of Microbiology and Virology of the National Academy of Sciences of Ukraine, \\ Acad. Zabolotnogo str., 154, Kyiv, 03143, Ukraine
}

*Corresponding author: gladkagv@ukr.net

UV irradiation is known to cause harmful effects on microorganisms. As a result, microorganisms have developed protection against exposure to harmful UV irradiation. We suggested that resistance to UV might be a specific characteristic of certain genera of microorganisms. So, the aim of the work is to assess whether there is a correlation between UV resistance and the taxonomic position of microorganisms or it is the adaptation of cells to extreme conditions. The study involved 67 strains from extreme ecosystems (phytocenoses and ornithogenic soil of the Antarctic, hypersaline ecosystems of the Crimea and the Dead Sea, the lake Baikal). The sequence of 16S rRNA genes, phylogenetic analysis and UV resistance were performed according to standard procedures. Phylogenetic analysis revealed live representatives of the following genera: Pseudomonas, Serratia, Rheinheimera, Aeromonas, Buttiauxella, Brevundimonas, Sphingomonas, Sphingopyxis, Dermacoccus, Frondihabitans, Microbacterium, Rhodococcus, Janthinobacterium, Arthrobacter, Micrococcus, Kocuria, Sphingobacterium, Flavobacterium, Chryseobacterium, Bacillus, Staphylococcus, Paenibacillus, and Sporosarcina. Gram-positive bacteria were significantly more resistant to UV irradiation $\left(\operatorname{LD}_{99.99} 750-1400 \mathrm{~J} / \mathrm{m}^{2}\right)$. Gram-negative had lower resistance $\left(\mathrm{LD}_{99.99} 35-150 \mathrm{~J} / \mathrm{m}^{2}\right)$. Most pigmented strains were more resistant to UV than non-pigmented ones. According to the values of lethal doses of UV irradiation we suggest that investigated microorganisms have effective mechanisms to repair DNA damages. Resistance of microorganisms to UV was not found to be related to the ecological features of their habitat. Thus, there is a correlation between the resistance of microorganisms to UV irradiation and their taxonomic position, which allows considering UV resistance as a diagnostic feature at the genus level.

Keywords: UV irradiation, resistance, phylogenetic analysis, taxonomic position. 


\section{Introduction}

The investigation of ultraviolet radiation influence on microorganisms is becoming an increasingly relevant topic of research today. It is related with the growing anthropogenic impact on the atmosphere. It leads to the destruction of the ozone layer protecting the Earth from the harmful effects of ultraviolet. Ultraviolet radiation on the Earth's surface is noted to be increased from about $5 \%$ to $20 \%$ (depending on latitude) by the end of the $21^{\text {st }}$ century (Zepp et al., 2011). Such intensity may affect a significant part of living organisms having a great ecological importance in biochemical cycles.

It is known that UV radiation is one of the most harmful abiotic factors. UV rays cause various physiological effects depending on the spectrum and dose of radiation. They adversely affect all living organisms, including bacteria, damaging such vital biomolecules as proteins, lipids and DNA (Ayala et al., 2014; Gabani, et al., 2013; Santos et al., 2013; Wynn-Williams et al., 2002). Therefore, microorganisms, especially from extreme ecosystems, have developed various mechanisms of protection against damage caused by UV radiation. Protection of bacteria from UV irradiation includes UV protective pigments (Dieser et al., 2010; Fernandez et al., 2006), effective reparation mechanisms to recover DNA damage induced by UV rapidly (Arrieta et al., 2000), and active protection against UV-induced oxidative stress (Chen et al., 2009). The ability of microorganisms to survive at high levels of UV irradiation is associated with the stability of their genome (Goosen et al., 2008; Singh et al., 2011). Bacteria resistant to UV radiation have been reported (Singh et al., 2011; Gabani et al., 2014) to be capable to produce the metabolites of the primary and secondary metabolism for their protection. According to the literature (Sinha et al., 1998), cyanobacteria have developed mechanisms for counteraction to UV radiation.

Some bacteria are adapted to survive under the pressure of UV irradiation. The molecular mechanisms helping microorganisms to adapt in the natural environment are not discovered yet. However, the so-called hypothetical mechanism has been proposed to provide the survival of radiation-sensitive extremophiles (Singh et al., 2011).

The UV irradiation is known to be able to act as an independent factor as well as in the combination with other environmental factors. Extreme ecosystems that we studied are characterized by a combination of abiotic factors. Thus, the Antarctic is recognized as the extreme geographically isolated region with low temperature, multiple freezing and thawing and wet-dry cycles, low nutrient levels, dehydration and high levels of solar UV radiation caused as the result of the destruction of the ozone layer in the atmosphere of the region (Adlam et al., 2010, Arrieta et al., 2000; Wynn-Williams et al., 1990). Hypersaline ponds occurring in all climatic zones on different continents also belong to the extreme regions on the planet (Grant et al., 2004). Hypersaline ecosystems of the Dead Sea and the Crimea are primarily characterized by high temperature, saltiness and high levels of UV radiation.

So, it is necessary to investigate the diversity of ultraviolet radiation resistant microorganisms from such environments in order to study in future the physiological mechanisms providing survival of microorganisms under the pressure of ultraviolet radiation (Gabani et al., 2014). We did not find data on the UV resistance of microorganisms of investigated ecosystems in the literature available for us. Moreover, there was no information about the correlation between the UV resistance and the taxonomic position of the microorganisms of any biotopes.

So, the aim of the work is to assess whether UV resistance of microorganisms correlates with their taxonomic position or it is the adaptation of cells to extreme conditions.

Previously, the investigation of resistance (or sensitivity) to UV radiation of microorganisms isolated from different extreme regions showed that this factor was not always associated with the level of solar (or other short-wave) radiation in their natural habitats (Romanovskaya et al., 2013; Romanovskaya et al., 2014; Vasileva-Tonkova et al., 2014). We have suggested the UV radiation resistance to be the characteristic of certain genera of microorganisms (or taxa of another level). Previously we have studied UV resistance of microorganisms from various extreme ecosystems and regions (phytocenoses and ornithogenic soil of the Antarctic) (Romanovskaya et al., 2014; Vasileva-Tonkova et al., 2014), hypersaline basins of the Crimea and biotopes of the Dead Sea (Romanovskaya et al., 2013), phytocenoses and soil of the 10-km zone of the Chernobyl nuclear power plant contaminated by radiation after the disaster in 1986 (Romanovskaya et al., 1999). So, the current work continues our research in the field of microbial UV-resistance. 


\section{Methods}

Aerobic chemoorganotrophic microorganisms described earlier (Romanovskaya et al., 2013; Romanovskaya et al., 2014; Vasileva-Tonkova et al., 2014) were investigated. They were isolated at $1-5^{\circ} \mathrm{C}$ or $30^{\circ} \mathrm{C}$ from phytocenoses and ornithogenic soil of the Western Antarctic, the hypersaline ecosystems of the Dead Sea and the therapeutic mineralized mud lakes of the Crimea (isolated at $42^{\circ} \mathrm{C}$ ). Also, some part of strains was presented to us by our colleagues from the Limnological Institute of the Siberian Branch of the Russian Academy of Sciences. These strains were isolated from the low-temperature region of shallow water biofilms formed on the plates of rocks and from deep (500-1400 m) ecosystems of the lake Baikal. The investigated strains are stored in the collection of the department of biology of extremophilic microorganisms of the Zabolotny Institute of Microbiology and Virology of the National Academy of Sciences of Ukraine. Strains isolated from the Antarctic and hypersaline ecosystems were cultivated on Nutrient Agar (NA) medium (HiMedia Laboratories Pvt. Ltd.) or meat-peptone agar medium (MPA) and glucose-potato agar medium (GPA). The standard agarized medium R-2A (agar Fluka Analytical, code: 17209) was used for cultivation of the Baikal strains. To suppress the growth of filamentous fungi, nystatin was added to the media at the concentration 50 $\mathrm{mg} / \mathrm{L}$. Psychrotolerant microorganisms were cultivated at the temperature of $18-20^{\circ} \mathrm{C}$, mesophilic microorganisms at $30^{\circ} \mathrm{C}$, and thermotolerant microorganisms at $42^{\circ} \mathrm{C}$.

Phylogenetic affiliation of bacterial isolates was determined by $16 \mathrm{~S}$ rRNA gene sequence analyses. Purification and sequencing of rDNA PCR products were performed by Macrogen Inc. (South Korea). The small-subunit rRNA gene was amplified from the extracted DNA using universal bacterial primers specific to $16 \mathrm{~S}$ rRNA gene 27L (5'-3': AGAGTTTGATCATGGCTCAG) and 1542R (5'-3': CAKAAAGGAGGTGATCC) (Belkova, 2009) as described previously (Romanovskaya et al., 2014; Romanovskaya et al., 2014a; Vasileva-Tonkova et al., 2014). Obtained sequences of bacterial isolates were compared with sequences deposited in GenBank database at [http://blast. ncbi.nlm.nih.gov/Blast.cgi] using BLAST search analysis to determine their closest relatives and phylogenetic affiliation. Phylogenetic position was determined by construction of the tree showing the taxonomic position of the studied strains among closely related and typical species (program ClustalX 2.1, Mega v. 6.00). Phylogenetic analyses of gene sequence data were conducted using the neighbor-joining ( $\mathrm{NJ}$ ) method. The reliability of internal branches was assessed from 1000 bootstrap pseudoreplicates.

The UV-resistance (UV-C) of microorganisms was determined as described previously (Romanovskaya et al., 2013; Romanovskaya et al., 2014a). UV irradiation of microorganisms was carried out using BUF- 15 lamp, $\lambda=254$ $\mathrm{nm}$. The exposure time was from 1 to $40 \mathrm{~min}(40-1600 \mathrm{~J} /$ $\left.\mathrm{m}^{2}\right)$. The dose of irradiation $\left(\mathrm{J} / \mathrm{m}^{2}\right)$ was determined using a DAU-81 dosimeter. To quantify microbial UV-resistance the lethal dose of UV was calculated. The UV dose that causes the death of $99,99 \%$ cells $\left(\mathrm{LD}_{99.99}\right)$ was calculated.

The experiments were carried out in triplicate. The obtained data were processed statistically applying Microsoft Office Excel software package. The reliability of the results of the studies was assessed according to the Student's t-test, taking the differences as statistically significant at the level of $p \leq 0.05$.

\section{Results and Discussion}

Phylogenetic analysis based on 16S rRNA gene sequencing revealed the affiliation of bacterial isolates from the extreme regions to the following family: Micrococcaceae, Nocardiaceae, Dermacoccaceae, Microbacteriaceae, Pseudomonadaceae, Xanthomonadaceae, Enterobacteriaceae, Chromatiaceae, Aeromonadaceae, Caulobacteraceae, Sphingomonadaceae, Alcaligenaceae, Oxalobacteraceae, Sphingobacteriaceae, Flavobacteriaceae, Bacillaceae, Staphylococcaceae, Paenibacillaceae, Planococcaceae.

The taxonomic position of bacterial isolates was established by phylogenetic analysis using the 16S rRNA gene sequence. Pigmented and/or spore-forming strains were identified among the isolated bacteria.

Table 1 shows the results regarding the sensitivity of bacteria from extreme biotopes (the Antarctic, hypersaline ecosystems of the Crimea and the Dead Sea, the lake Baikal) to UV as well as their determined taxonomic position. UV resistance inherent to isolates from extreme biotopes with enhanced insolation, etc. was not also excluded. It helped to determine whether there is a correlation between the resistance of microorganisms to UV radiation and their taxonomic position (Table 1). 
Table 1. Bacteria isolated from extreme biotopes and their resistance to UV ( $\left.L D_{99.99}\right)$

\begin{tabular}{|c|c|c|c|}
\hline $\begin{array}{l}\text { Family of } \\
\text { microorganisms }\end{array}$ & Species, strain & Region of isolation & $\mathrm{UV}, \mathrm{LD}_{99.99} \mathrm{~J} / \mathrm{m}^{2}$ \\
\hline \multicolumn{4}{|c|}{ Phylum Actinobacteria } \\
\hline \multirow{5}{*}{ Micrococcaceae } & Arthrobacter scleromae $28 \mathrm{r} 5 \mathrm{~g}$ & \multirow{3}{*}{ Antarctic } & 240 \\
\hline & Micrococcus luteus 0-1 & & 220 \\
\hline & Rothia sp. 0-11 & & 300 \\
\hline & Kocuria sp. 3A & \multirow{2}{*}{ Lake Baikal, shallow water } & 600 \\
\hline & Micrococcus sp. 3, 11 & & $200-280$ \\
\hline \multirow{2}{*}{ Nocardiaceae } & Rhodococcus fascians 181n3 & Antarctic & 280 \\
\hline & Rhodococcus sp. 3, 16 & Lake Baikal, $500 \mathrm{~m}$ & $180-280$ \\
\hline Dermacoccaceae & Dermacoccus profundi U9 & Antarctic & 600 \\
\hline \multirow{4}{*}{ Microbacteriaceae } & Frondihabitans sp. 4r5, 5r5, 40r5, U11 & \multirow{3}{*}{ Antarctic } & $110-120$ \\
\hline & Microbacterium trichothecenolyticum 0-3 & & 165 \\
\hline & Microbacterium foliorum 0-6 & & 320 \\
\hline & Microbacterium sp. 10 & Lake Baikal, 500 m & 180 \\
\hline \multicolumn{4}{|c|}{ Phylum Proteobacteria (class Gammaproteobacteria) } \\
\hline \multirow{4}{*}{ Pseudomonadaceae } & Pseudomonas mandelii U1 & \multirow[b]{2}{*}{ Antarctic } & 80 \\
\hline & $\begin{array}{c}\text { Pseudomonas fluorescens } \\
\text { R3, R5 }\end{array}$ & & $115-130$ \\
\hline & Pseudomonas sp. 4, 6A & Lake Baikal, shallow water & $50-80$ \\
\hline & Pseudomonas sp. 38 & Lake Baikal, 500 m & 70 \\
\hline Xanthomonadaceae & Stenotrophomonas rhizophila U10 & Antarctic & 190 \\
\hline \multirow{4}{*}{ Enterobacteriaceae } & Serratia sp. 6rlg & Antarctic & 70 \\
\hline & Serratia sp. 1A, 10 & Lake Baikal, shallow water & $35-50$ \\
\hline & Serratia sp. 9 & \multirow{4}{*}{ Lake Baikal, 500 m } & 135 \\
\hline & Buttiauxella sp. $21 \mathrm{~m}$ & & 65 \\
\hline Chromatiaceae & Rheinheimera sp. 61 & & 110 \\
\hline Aeromonadaceae & Aeromonas sp. 15m & & 40 \\
\hline \multicolumn{4}{|c|}{ Phylum Proteobacteria (class Alphaproteobacteria) } \\
\hline \multirow{2}{*}{ Caulobacteraceae } & Brevundimonas vesicularis 0-8 & Antarctic & 200 \\
\hline & Brevundimonas sp. $37,43,47$ & \multirow{3}{*}{ Lake Baikal, 500 m } & $100-140$ \\
\hline \multirow{2}{*}{ Sphingomonadaceae } & Sphingomonas sp. 21 & & 120 \\
\hline & Sphingopyxis sp. 45 & & 90 \\
\hline \multicolumn{4}{|c|}{ Phylum Proteobacteria (class Betaproteobacteria) } \\
\hline Alcaligenaceae & Achromobacter sp. 49 & \multirow{2}{*}{ Lake Baikal, 500 m } & 160 \\
\hline Oxalobacteraceae & Janthinobacterium sp. $33 \mathrm{~m}$ & & 70 \\
\hline \multicolumn{4}{|c|}{ Phyla Bacteroidetes } \\
\hline Sphingobacteriaceae & Sphingobacterium anhuiense U3 & Antarctic & 260 \\
\hline
\end{tabular}




\begin{tabular}{|c|c|c|c|}
\hline $\begin{array}{l}\text { Family of } \\
\text { microorganisms }\end{array}$ & Species, strain & Region of isolation & UV, $\operatorname{LD}_{99.99} \mathrm{~J} / \mathrm{m}^{2}$ \\
\hline \multirow{2}{*}{ Flavobacteriaceae } & Flavobacterium sp. $38 \mathrm{~m}$ & \multirow{2}{*}{ Lake Baikal, 500 m } & 280 \\
\hline & Chryseobacterium sp. $61 \mathrm{~m}$ & & 80 \\
\hline \multicolumn{4}{|c|}{ Phylum Firmicutes } \\
\hline \multirow{8}{*}{ Bacillaceae } & Bacillus licheniformis 7t1 & \multirow{6}{*}{$\begin{array}{l}\text { Hypersaline environments of } \\
\text { the Crimea and the Dead Sea }\end{array}$} & 1500 \\
\hline & B. subtilis subsp. subtilis $7 \mathrm{t} 3$ & & 1100 \\
\hline & B. subtilis subsp. spizizenii R1 & & 1300 \\
\hline & Bacillus simplex 1t4, 3s2 & & $800-1400$ \\
\hline & Bacillus mojavensis R6 & & 1200 \\
\hline & Bacillus sp. 1t2, 1t5, 6t2 & & $1200-1250$ \\
\hline & Bacillus sp. 2A, 2B, 3B, 5B, 2C, 8, 9,12A & Lake Baikal, shallow water & $420-1000$ \\
\hline & Bacillus sp. 44 & Lake Baikal, 500 m & 800 \\
\hline \multirow{2}{*}{ Staphylococcaceae } & Staphylococcus sp. 6t1 & Dead Sea & 400 \\
\hline & Staphylococcus sp. 0-10 & Antarctic & 300 \\
\hline Paenibacillaceae & Paenibacillus sp. 5A, 7, 12B & Lake Baikal, shallow water & $400-720$ \\
\hline Planococcaceae & $\begin{array}{c}\text { Sporosarcina aquimarina } \\
\text { 0-7, 0-9 }\end{array}$ & Antarctic & $480-540$ \\
\hline
\end{tabular}

Note. $p \leq 0.05$

The majority of bacteria of Antarctic phytocoenoses and soils were resistant to UV. The results showed that the lethal dose of UV ( $\left.\mathrm{LD}_{99.99}\right)$ for most bacterial strains was in the range $\sim 200-500 \mathrm{~J} / \mathrm{m}^{2}$. The exception was bacteria Pseudomonas mandelii U1, P. fluorescens R3 and R5, Serratia sp. 6r1g, Frondihabitans sp. U11, 4r5, 5r5, 40r5. Apparently, it is due to the fact that classical representatives of Pseudomonas, as well as other proteobacteria, are sensitive to UV ( $\operatorname{LD}_{99.99}$ usually is in the range $40-100$ $\mathrm{J} / \mathrm{m}^{2}$ ) (Romanovskaya et al., 2011). The strains isolated from the black moss on the southern side of the vertical cliffs (rocks), Sporosarcina aquimarina 0-7 and 0-9, were the most resistant to UV among the Antarctic bacteria (480-540 J/m²) (Belkova, 2009).

Since the ecosystems of the Dead Sea and the Crimea are almost always open to the Sun, the UV resistant bacteria are to be present there. All studied bacteria showed resistance to UV radiation (Romanovskaya et al., 2002). The lethal dose of UV ( $\left(\mathrm{LD}_{99.99}\right)$ for strains of the spore-forming genus Bacillus was $750-1500 \mathrm{~J} / \mathrm{m}^{2}$; for Staphylococcus sp. 6 t1 (does not form spores) $-400 \mathrm{~J} / \mathrm{m}^{2}$.

Analyzing the effect of UV irradiation on the survival of spore-forming bacteria we suggested that the damage minimization under UV radiation could be provided by spore formation. For instance, spores of Bacillus subtilus are protected by a thin protein layer from the damaging effect of UV-B and UV-C and solar UV. Layer-free mutants were very sensitive to these factors (Romanovskaya et al., 2014b). Spores of Bacillus subtilus contain DNA-bound protein protecting spore DNA from the brakes induced by UV or desiccation (Riesenmann et al., 2000).

Microbial spores are shown to be highly resistant to a wide variety of physical stresses such as: wet and dry heat, UV and gamma radiation, oxidizing agents, chemicals, and extremes of both vacuum and ultrahigh hydrostatic pressure (Nicholson et al., 2002). According to the results of biochemical, genetic and molecular biological studies, molecular models have been developed that describe the spores of bacteria and vegetative $B$. subtilis cells resistant to action of bactericidal agents such as ultraviolet radiation, heat, and oxidative damage (Gerhardt et al., 1989; Nicholson et al., 2000).

Under natural conditions, the Baikal strains are not exposed to solar radiation due to the peculiarities of their habitats. Therefore, these isolates could be assumed to be sensitive to UV radiation. However, comparing the 
lethal UV doses for the Baikal strains isolated from biofilms formed on rocks, most of them turned out to be resistant to high UV doses. First of all, there were the strains of genera: Bacillus and Paenibacillus ( $\mathrm{LD}_{99.99}$ was $400-1000 \mathrm{~J} / \mathrm{m}^{2}$ ), able to form spores in ungodly conditions. Representatives of Actinobacteria (strains Kocuria and Micrococcus) were also resistant to UV ( $\mathrm{LD}_{99.99}$ was 200-600 J/m²). Gram-negative bacteria Serratia sp. and Pseudomonas sp. were sensitive to UV irradiation. The $\mathrm{LD}_{99.99}$ was $35-80 \mathrm{~J} / \mathrm{m}^{2}$ for them.

It was suggested that gram-positive bacteria are better suited to ultraviolet irradiation, since their cell walls swallow a significant portion of UV radiation (Jagger, 1985), which coincides with our results.

Also, the influence of UV on the survival of bacteria from the deep (500-1400 m) ecosystems of the lake Baikal (water, sediments and cochlea Gastropoda) was studied. Investigated strains are not exposed to UV radiation in natural conditions due to the deep location in the lake Baikal. Therefore, these strains could be assumed to be sensitive to UV radiation. However, when determining the lethal doses of UV for the studied strains, some of them were shown to be resistant to high doses of UV. The bacterial strain Bacillus sp. 44 was highly resistant to UV irradiation. It is consistent with the general trend of bacilli to UV resistance as it was previously shown for bacilli isolated from biofilms formed on rocks plates. Also, Flavobacterium sp. and Rhodococcus sp. were resistant to UV. The $\mathrm{LD}_{99.99}$ for them was $280 \mathrm{~J} / \mathrm{m}^{2}$. Gram-negative bacteria of genera Brevundimonas, Achromobacter, Rheinheimera (phylum Proteobacteria) were sensitive to UV. $\mathrm{LD}_{99.99} \mathrm{UV}$ for them varied within $100-160 \mathrm{~J} / \mathrm{m}^{2}$. No differences relative to UV resistance were found between the strains isolated at different depths of water (from $500 \mathrm{~m}$ to $1400 \mathrm{~m}$ ).

What mechanism of UV resistance is realized by microorganisms isolated from the deep zones of the lake Baikal and from biofilms formed on plates of rocks? There are several mechanisms of UV resistance inherent in all organisms: the presence of pigments that minimize cell damage, sporulation, photoreparation and mechanisms of dark reparation of DNA damages (Arrieta et al., 2000; Dieser et al., 2010; Fernandez et al., 2006). Isolated Baikal strains that differ in the level of UV resistance (genera: Serratia, Pseudomonas, Kocuria, Bacillus and Paenibacillus) are unpigmented and, therefore, they have no mechanisms to minimize cell damage due to pigments (melanines, carotenoides, etc.). We eliminated the photoreparation process, since UV irradiation and further incubation of irradiated microorganisms were carried out in the darkness. The presence of effective systems of dark reparation of DNA damage in cells is the most important to repair DNA damages occurring due to various types of radiation, including solar short-wave UV radiation. The high UV resistance of some Baikal isolates suggests them to have active systems of dark reparation of DNA damages. Considering that Baikal microorganisms are constantly under stress in natural environment, their high adaptive potential allows them to actively launch various mechanisms to survive, expressed in effective DNA reparation as well as in the ability to quickly launch sporulation processes.

So, during the investigation, the attention was drawn to the following regularities revealed when 67 isolates from the studied biotopes were compared (Table 1):

Gram-positive bacteria (genera: Kocuria, Microbacterium, Arthrobacter, Paenibacillus and Bacillus) are more resistant to UV than Gram-negative (genera: Serratia, Pseudomonas, etc.); therefore, resistance may depend on the composition of the cell wall; spore forms (genera Bacillus and Paenibacillus) have significantly higher UV resistance than non-sporulating ones; apparently, the survival strategy of spore-forming bacteria under the UV radiation (DNA-damaging factor) is provided both by the mechanism that minimizes DNA damages (the presence of spores) and the effective mechanisms of DNA damages reparation;

most pigmented microorganisms (genera: Microbacterium, Arthrobacter, Rhodococcus and others) have higher UV resistance than unpigmented microorganisms; thus, resistance to short-wave radiation (in particular, to ultraviolet radiation) can be caused by the presence of spores or pigmentation, that is, external protection of cells from radiation and by the presence of effective mechanisms of DNA damages reparation; resistance of microorganisms to UV was not found to be related to the ecological features of their habitat; the exception is hypersaline reservoirs (lakes of the Crimea and the coast of the Dead Sea), where mainly spore-forming unpigmented strains of Bacillus were detected. 
Basing on the results obtained, it can be considered that there is a correlation between the resistance of microorganisms to UV and their taxonomic position, but not their habitat. The collected data were evidenced by the several independent investigations. Thus, Agogue et al. (2005) reported that no relationship was found between the sensitivity of the isolates to solar radiation and the habitat from which they had been isolated (i.e., surface microlayer or underwater). That is, in surface microlayers and groundwater, radiation resistance is well distributed among bacteria. No correlation was found between the sample depth in the Chesapeake Bay (Bailey et al., 1983). Also, studying samples in the northern Adriatic Sea marine snow (from a 10- to 20-m depth), the top 0 to $2 \mathrm{~mm}$ of the sandy sediment ( $\approx 25$-m depth) and ambient water (from a 10- to 20-m depth), no direct correlation was found between the ultraviolet sensitivity of the isolates and the isolation point (Arrieta et al., 2000). The number of UV-resistant subsurface and surface soil bacterial isolates was shown to be similar (31\% and $26 \%$, respectively) (Arrage et al., 1993). Thus, the investigated literature data and our results confirm that the resistance or sensitivity of microorganisms to UV radiation is not related to the ecological features of their habitat.

Thus, all isolates of Proteobacteria represented by genera Serratia, Pseudomonas, Buttiauxella, Brevundimonas,

\section{References}

Adlam L.S., Balks M.R., Seybold C.A., Campbell D.I. (2010) Temporal and spatialvariation in active layer depth in the McMurdo Sound Region, Antarctica. Antarct Sci. 22(01): 45-52. https://doi. org/10.1017/S0954102009990460

Agogue H., Joux F., Obernosterer I., Lebaron P. (2005) Resistance of marine bacterioneuston to solar radiation. Appl. and Environ. Microbial. 71: 5282-5289. https://doi.org/10.1128/ AEM.71.9.5282-5289.2005

Arrage A.A., Phelps TJ., Benoit R.E. and White D.C. (1993) Survival of subsurface microorganisms exposed to uv radiation and hydrogen peroxide. Appl. and Environ. Microbial. 59(11): 35453550. https://doi.org/10.1128/AEM.59.11.3545-3550.1993

Arrieta J.M. Weinbauer M.G., Herndl G.J. (2000) Interspecific differences in sensitivity to UV radiation and subsequent recovery in selected isolates of marine bacteria. Appl. Environ. Microbiol. 66: 1468-1473. https://doi.org/10.1128/AEM.66.4.1468-1473.2000
Sphingomonas, Janthinobacterium were UV-sensitive, regardless of the biotopes of their isolation. Most isolates of Actinobacteria were resistant to UV (genera: Microbacterium, Rhodococcus, Arthrobacter, Kocuria). At the same time, all strains of Frondihabitans (as well as Actinobacteria, Micrococcaceae family) were sensitive to UV. Consequently, there are both highly resistant (genus Kocuria) and UV-sensitive bacteria (genus Frondihabitans) among the one family. Both resistant (genera: Flavobacterium, Sphingobacterium) and UV-sensitive bacteria (genus Chryseobacterium) were detected among isolated strains of Bacteroidetes. Only highly resistant genera Bacillus, Paenibacillus and Sporosarcina were found among the Firmicutes.

\section{Conclusions}

Taking into account that there is a correlation between the resistance of microorganisms to UV and their affiliation to some taxon, UV resistance can be a diagnostic sign of bacteria at the level of genus and some higher taxa. Estimating the overall results, we can assume that resistance or sensitivity to UV is genetically fixed in the representatives of various taxa of microorganisms.

Ayala A., Munoz M. F., Arguelles S. (2014). Lipid peroxidation: production, metabolism, and signaling mechanisms of malondialdehyde and 4-hydroxy-2-nonenal. Oxid. Med. Cell. Longev. Available at: https://doi.org/10.1155/2014/360438

Bailey C., Neihof R. and Tabor P. (1983) Inhibitory effect of solar radiation on amino acid uptake in Chesapeake Bay bacteria. Appl. Environ. Microbiol. 46: 44-49. https://doi.org/10.1128/ AEM.46.1.44-49.1983

Blanco Y., Prieto-Ballesteros O., Gómez M.J., Moreno-Paz M., García-Villadangos M., Rodríguez-Manfredi J.A., Cruz-Gil P., Sánchez-Roman M., Rivas L.A., Parro V. (2012) Microbial populations description in Deception Island (Antarctica): exploring the surface and the permafrost using an antibody microarray. In: Abstracts 7 of European Planetary Science Congress.- EPSC2012-173-1.

Belkova N.L. (2009) Molecular genetic methods for the analysis of microbial communities. In the book. Diversity of microbial 
communities in inland water reservoirs of Russia: Educational-methodical manual. Teaching aid. Ed. Andreeva A.M.: Yaroslavl pub. LLC «Print House», 53-63.

Chen L. Z., Wang G. H., Hong S., Liu A., Li C., Liu Y. D. (2009) UV$\mathrm{B}$-induced oxidative damage and protective role of exopolysaccharides in desert cyanobacterium Microcoleus vaginatus. J. Integr. Plant Biol. 51: 194-200. https://doi.org/10.1111/j.17447909.2008.00784.x

DasSarma S. and DasSarma P. (2017) Halophiles. In eLS, John Wiley \& Sons, Chichester, UK. Available at: https://doi. org/10.1002/9780470015902.a0000394.pub4

Dieser M., Greenwood M., Foreman C.M. (2010) Carotenoid pigmentation in Antarctic heterotrophic bacteria as a strategy to withstand environmental stresses. Arct. Antarct. Alp. Res. 42: 396-405. https://doi.org/10.1657/1938-4246-42.4.396

Fernandez Zenoff V., Sineriz F., Farovas M.E. (2006) Diverse responses to UV-B radiation and repair mechanisms of bacteria isolated from high-altitude aquatic environments. Appl. Environ. Microbiol. 72: 7857-7863. https://doi.org/10.1128/AEM.01333-06

Gabani P., Prakash D., Singh O.V. (2014) Bio-signature of Ultraviolet-Radiation-Resistant Extremophiles from Elevated. American Journal of Microbiological Research 2(3): 94-104. https:// doi.org/10.12691/ajmr-2-3-3

Gabani P., Singh O.V. (2013) Radiation-resistant extremophiles and their potential in biotechnology and therapeutics. Applied Microbiology Biotechnology 97: 993-1004.https://doi.org/10.1007/ s00253-012-4642-7

Gerhardt P., Marquis R.E. (1989) Spore thermoresistance mechanisms. In: Smith I, Slepecky R A, Setlow P, editors. Regulation of procaryotic development. Washington, D.C.: Americ. Society for Microbiol.: 43-63.

Goosen N., Moolenaar G.F. (2008) Repair of UV damage in bacteria. DNA Repair 7: 353-379. https://doi.org/10.1016/j. dnarep.2007.09.002

Grant W.D. (2004) Life at low water activity Phil. Trans. Roy. Soc. Lon. Ser. B. Biol. Sci. Eds: W. D. Grant. 359(1448): 1249-1267. https://doi.org/10.1098/rstb.2004.1502

Jagger J. 1985. Solar UV actions on living cells. Praeger, New York.

Nicholson W.L., Fajardo-Cavazos P., Rebeil R., Slieman T.A., Riesenman P.J., Law J.F. \& Xue Y. (2002) Bacterial endospores and their significance in stress resistance. Antonie van Leeuwenhoek 81: 27-32 Available at: https://link. springer.com/article/10.1023/A:1020561122764 https://doi. org/10.1023/A:1020561122764

Nicholson W.L., Munakata N., Horneck G., Melosh H.J., Setlow P. (2000) Resistance of Bacillus endospores to extreme ter- restrial and extraterrestrial environments. Microbiol. Mol. Biol. Rev. 64(3): 548-572. https://doi.org/10.1128/MMBR.64.3.548572.2000

Oren A., Bardavid R.E. and Mana L. (2014) Perchlorate and halophilic prokaryotes: implications for possible halophilic life on Mars. Extremophiles 18: 75-80. https://doi.org/10.1007/ s00792-013-0594-9

Riesenmann P.J., Nicolson W.L. (2000) Role of the spore coate layers in Bacillus subtilis spore resistance to hydrogen peroxide, artificial UV-C, UV-B, and solar UV radiation. Appl. Environ. Microbiol 66(2): 620-626. https://doi.org/10.1128/AEM.66.2.620626.2000

Romanovskaya V.A., Avdeeva L.V., Gladka G.V., Pritula I.R., Kharkhota M.A., Tashyrev A.B. (2013) Resistance to extremal factors of microorganisms of coastal ecosystems of the Dead Sea. Mikribiol. Zhurnal 75(3): 3-11.

Romanovskaya V., Gladka G., Tashyrev O. (2014b) Autecology of microorganisms of coastal ecosystems of the Dead Sea. Ecological Engineering and Environment Protection 4(5): 44-49.

Romanovskaya V.A., Parfenova V.V., Belkova N.L., Sukhanova E.V., Gladka G.V., Tashyrev A.B. (2014a) Autecology, taxonomy, and strategy of surviving in extreme condition for antarctic microorganisms. Fundamental research 11(9): 1954-1959.

Romanovskaya V.A., Parfenova V.V., Belkova N.L., Sukhanova E.V., Gladka G.V., Tashyreva A.A. (2014) Phylogenetic analysis of bacteria of extreme ecosystems. Mikribiol. Zhurnal 76(3): 3-10.

Romanovskaya V.A., Rokitko P.V., Malashenko Yu.R., Chernaya N.A. (1999) Sensitivity of soil bacteria isolated from the alienated zone around the Chernobyl nuclear pover plant to various stress factors. Microbiology 68(4): 534-539.

Romanovskaya V.A., Rokitko P.V., Mikheev A.N., Gushcha N.I., Malashenko Yu.R., Chernaya N.A. (2002) The effect of $\mathrm{y}$-radiation and desiccation on the viability of the soil bacteria isolated from the alienated zone around the chernobyl nuclear power plant. Microbiology 71(5): 608-613. https://doi. org/10.1023/A:1020575223365

Romanovskaya V.A., Tashyrev A.B., Shilin S.O., Chernaya N.A., Rokitko P.V., Levishko A.S. (2011) Resistance of antarctic microorganisms to UV radiation. Mikribiol. Zhurnal 73(3): 3-8.

Romanovskaya V., Gladka G., Tashyrev 0. (2014b) Autecology of microorganisms of coastal ecosystems of the Dead Sea. Ecological Engineering and Environment Protection 4(5): 44-49.

Santos A.L., Oliveira V., Baptista I., Henriques I., Gomes N.C., Almeida A., et al. (2013) Wavelength dependence of biological damage induced by UV radiation on bacteria. Arch. Microbiol 195: 63-74. https://doi.org/10.1007/s00203-012-0847-5

Singh O.V., Gabani P. (2011) Extremophiles: radiation resistance microbial reserves and therapeutic implications. Journal of Ap- 
plied Microbiology 110: 851-861. https://doi.org/10.1111/j.13652672.2011.04971.x

Sinha R.P., Klisch M., Groniger A., Hader D. (1998). Ultraviolet-absorbing/screening in cyanobacteria, phytoplankton and macroalgae. J. Photochem. Photobiol. B. 47: 82-94. https://doi. org/10.1016/S1011-1344(98)00198-5

Janssen P.H. (2006) Identifying the dominant soil bacterial taxa in libraries of $16 \mathrm{~S}$ rRNA and 16S rRNA genes. Applied and Environmental Microbiology 72: 1719-1728. https://doi.org/10.1128/ AEM.72.3.1719-1728.2006

Vasileva-Tonkova E., Romanovskaya V., Gladka G., Gouliamova D., Tomova I., Stoilova-Disheva M., Tashyrev O. (2014) Ecophysiological properties of cultivable heterotrophic bacteria and yeasts dominating in phytocenoses of Galindez Island, maritime Antarctica. World Journal of Microbiology and
Biotechnology 30(4): 1387-1398. https://doi.org/10.1007/ s11274-013-1555-2

Wynn-Williams D.D., Edwards H.G.M., Newton E.M., Holder J.M. (2002) Pigmentation as a survival strategy for ancient and modern photosynthetic microbes under high ultraviolet stress on planetary surfaces. International Journal of Astrobiology 1(1): 39-49. https://doi.org/10.1017/S1473550402001039

Yu L.Z., Luo X.S., Liu M., Huang Q. (2015) Diversity of ionizing radiation-resistant bacteria obtained from the Taklimakan Desert. J. Basic Microbiol. 55(1): 135-140. https://doi.org/10.1002/ jobm.201300390

Zepp R.G., Erickson D.J., Paul N.D., Sulzberger B. (2011). Effects of solar UV radiation and climiate change on biogeochemical cycling: interactions and feedbacks. Photochem. Photobiol. Sci. 10: 261-279. https://doi.org/10.1039/c0pp90037k 